\title{
Strategically Focusing on Focus Groups to Improve Organizational Climate
}

By: Michael Crumpton

Michael Crumpton. "Strategically Focusing on Focus Groups to Improve Organizational

Climate” Research Library Issues: A Report from ARL, CNI, and SPARC, no. 286 (2015): 8-17.

Made available courtesy of Association of Research Libraries:

http://publications.arl.org/rli286/8.

(c) The Author. Published under a Creative Commons Attribution License (CC BY 4.0); http://creativecommons.org/licenses/by/4.0/

\begin{abstract}
:
Complementing several successful implementations of the LibQUAL+ survey to assess library service quality, the University Libraries at the University of North Carolina at Greensboro (UNCG) decided to engage the ClimateQUAL survey1 in 2011 to gain perspective on changes that were occurring within the library staff organization as well as within the profession overall. At the time, the profession was seeing a greater need to justify resources and expenses overall, and the UNCG University Libraries was strategically implementing decisions made due to budget cuts, which impacted some positions and work flows within the organization.
\end{abstract}

Keywords: Libraries | Organizational climate | Assessment

***Note: Full text of article below 


\section{Strategically Focusing on Focus Groups to Improve Organizational Climate}

\section{Michael Crumpton, Assistant Dean for Administrative Services, University Libraries, University of North Carolina at Greensboro}

omplementing several successful implementations of the LibQUAL+ survey to assess library service quality, the University Libraries at the University of North Carolina at Greensboro (UNCG) decided to engage the ClimateQUAL survey ${ }^{1}$ in 2011 to gain perspective on changes that were occurring within the library staff organization as well as within the profession overall. At the time, the profession was seeing a greater need to justify resources and expenses overall, and the UNCG University Libraries was strategically implementing decisions made due to budget cuts, which impacted some positions and work flows within the organization.

UNCG Libraries convened a ClimateQUAL team that included the associate dean for public services, the assistant dean for administrative services, the human resources librarian, and the reference and diversity librarian in order to prepare and organize the libraries for administering the ClimateQUAL instrument. This team regularly consulted with the dean of libraries throughout the entire process.

The UNCG Libraries launched the survey in the fall of 2011, following several organizational changes either recently completed or announced within the organization, as well as a substantial budget cut for that year. It should also be noted that salary increases had been denied by the state for the previous three years and other departments on campus were conducting layoffs. No layoffs occurred at the University Libraries.

The UNCG ClimateQUAL team marketed the survey well to the entire libraries staff and arranged for special considerations in taking the survey, as well as activities surrounding the "event" such as refreshments. The team also explained and oriented staff to the survey protocol prior to implementation and answered staff questions in advance so as to ensure understanding of the survey's purpose and use.

The team presented the survey in conjunction with the University Libraries' mission statement, statement of values, and current strategic planning, asking staff to reflect upon organizational attributes as they were reflected by these collective commitments.

\section{UNCG Summary Data and Results}

The UNCG Libraries achieved a 91\% completion rate for staff taking the survey and presented results to the staff in the spring of 2012. Results were first shared as statistics and pie charts but were later simplified for ease of understanding and to facilitate the process of identifying issues that warranted attention. 


\section{UNCG Climate Measures with Highest Scores}

The following is a list of the 10 climate measures that the survey results showed as the University Libraries' "Strong Areas." The percentages reflect the number of employees who positively responded to the questions in each scale.

\begin{tabular}{|c|c|c|}
\hline "I agree, University Libraries has a climate for..." & UNCG & $\begin{array}{l}\text { Average of all ClimateQUAL } \\
\text { Libraries as of } 2011\end{array}$ \\
\hline $\begin{array}{l}\text { the extent to which the library supports diversity related to } \\
\text { sexual orientation. (Climate for Sexual Orientation) }\end{array}$ & $97 \%$ & $92 \%$ \\
\hline $\begin{array}{l}\text { the extent to which the library supports diversity related to race. } \\
\text { (Climate for Race) }\end{array}$ & $96 \%$ & $90 \%$ \\
\hline $\begin{array}{l}\text { the extent to which the library supports diversity of gender. } \\
\text { (Climate for Gender) }\end{array}$ & $90 \%$ & $89 \%$ \\
\hline $\begin{array}{l}\text { the degree to which equality between minorities and majorities } \\
\text { is valued; the extent to which the library values diversity and } \\
\text { diversity related initiatives. (Climate for Valuing Diversity) }\end{array}$ & $89 \%$ & $78 \%$ \\
\hline $\begin{array}{l}\text { valuing the usefulness and importance of teamwork. (Climate } \\
\text { for Benefits of Teamwork) }\end{array}$ & $88 \%$ & $82 \%$ \\
\hline $\begin{array}{l}\text { the degree to which employees perceive their work is important. } \\
\text { (Climate for Task Engagement) }\end{array}$ & $86 \%$ & $87 \%$ \\
\hline $\begin{array}{l}\text { the degree to which employees of authentic transformational } \\
\text { leaders report these leaders as being highly transparent-that is, } \\
\text { that the transformational leader is consistent in the actions, and } \\
\text { that the leader truly believes what he/she claims he/she believes. } \\
\text { (Climate for Authentic Transformational Leadership) }\end{array}$ & $85 \%$ & $72 \%$ \\
\hline $\begin{array}{l}\text { the degree to which employees perceive the quality of their } \\
\text { relationship with their immediate supervisors. (Climate for } \\
\text { Leader-Member Relationship Quality) }\end{array}$ & $84 \%$ & $79 \%$ \\
\hline $\begin{array}{l}\text { the degree to which new ideas are encouraged, accepted, and } \\
\text { rewarded among co-workers. (Climate for Innovation) }\end{array}$ & $83 \%$ & $80 \%$ \\
\hline $\begin{array}{l}\text { the degree to which one perceives there is fairness and } \\
\text { respectfulness between employees and supervisors. (Climate for } \\
\text { Interpersonal Justice) }\end{array}$ & $82 \%$ & $81 \%$ \\
\hline
\end{tabular}

These results seem to indicate a healthy organizational environment with regard to most diversity issues and this was generally supported by the comments. However, areas of concern did exist, as the next section illustrates, so measures were sorted and compared to all ClimateQUAL libraries in order to help the libraries focus on the areas in greatest need of attention. 


\section{UNCG Climate Measures with Lowest Scores}

The following is a list of the 10 climate measures that the UNCG survey results showed as the lowest scores.

\begin{tabular}{|c|c|c|}
\hline "I agree, University Libraries has a climate for... " & UNCG & $\begin{array}{l}\text { Average of all ClimateQUAL } \\
\text { Libraries as of } 2011\end{array}$ \\
\hline $\begin{array}{l}\text { the extent to which rewards received adequately reflect level of } \\
\text { effort and work (Climate for Justice-Distributive Justice) }\end{array}$ & $30 \%$ & $29 \%$ \\
\hline $\begin{array}{l}\text { the organization's structure and policies facilitate and encourage } \\
\text { teamwork (Climate for Teamwork-Structural Facilitation } \\
\text { of Teamwork) }\end{array}$ & $51 \%$ & $48 \%$ \\
\hline $\begin{array}{l}\text { fairness of procedures used to determine rewards; performance } \\
\text { evaluations, etc. (Climate for Justice-Procedural Justice) }\end{array}$ & $59 \%$ & $47 \%$ \\
\hline $\begin{array}{l}\text { the extent to which an individual feels they can contribute } \\
\text { to their team (Climate for Psychological Empowerment in } \\
\text { the Workplace) }\end{array}$ & $63 \%$ & $60 \%$ \\
\hline $\begin{array}{l}\text { the degree to which employees exhibit satisfaction with their work } \\
\text { (Climate for Job Satisfaction) }\end{array}$ & $68 \%$ & $93 \%$ \\
\hline $\begin{array}{l}\text { the degree to which an organization or teams therein encourage } \\
\text { employees to freely share opinions with each other and with } \\
\text { management (Climate for Psychological Safety) }\end{array}$ & $70 \%$ & $67 \%$ \\
\hline $\begin{array}{l}\text { the degree to which you feel you have access to the information } \\
\text { you need (Climate for Justice-Informational Justice) }\end{array}$ & $70 \%$ & $62 \%$ \\
\hline $\begin{array}{l}\text { the extent to which an individual employee is dedicated to staying } \\
\text { with, and feels positively about, this organization (Climate for } \\
\text { Organizational Commitment) }\end{array}$ & $71 \%$ & $66 \%$ \\
\hline $\begin{array}{l}\text { the consistency of application of procedures across subgroups } \\
\text { (Climate for Deep Diversity-Standardization of Procedures } \\
\text { across Groups) }\end{array}$ & $73 \%$ & $68 \%$ \\
\hline $\begin{array}{l}\text { continual learning that has policies, practices, and procedures } \\
\text { that emphasize continued employee education (Climate for } \\
\text { Continual Learning) }\end{array}$ & $73 \%$ & $68 \%$ \\
\hline
\end{tabular}

\section{Improvement Themes}

The UNCG ClimateQUAL team first shared these results at a University Libraries All Personnel Meeting. Later, the team held smaller information sessions in which individuals could ask questions and discuss perceptions of the results. From those sessions, the team decided to focus on three areas that were the most significant concerns of the staff: 
- Climate for Justice-Distributive Justice-extent to which rewards received adequately reflect level of effort and work

Data: UNCG ClimateQUAL: 30\% agreement; all ClimateQUAL libraries: 29\% agreement

Desired Change: Need to implement rewards, recognition, and appreciation for effort and work. Recognizing limitations to providing rewards locally, what else can be addressed to demonstrate value for work performed?

- Climate for Teamwork-Structural Facilitation of Teamwork-organization's structure and policies facilitate and encourage teamwork

Data: UNCG ClimateQUAL: 51\% agreement; all ClimateQUAL libraries: 48\% agreement

Desired Change: Need to develop a climate for teamwork among exempt, i.e., librarians, and nonexempt, i.e., paraprofessional, employees. (Challenge: disparity in the treatment of non-exempt employees compared with exempt employees or how to align responsibilities of different levels to capture benefit for both groups).

- Climate for Justice-Procedural Justice-fairness of procedures used to determine rewards; performance evaluations, etc.

Data: UNCG ClimateQUAL: 59\% agreement; all ClimateQUAL libraries: 47\% agreement

Desired Change: Need to build faculty and staff trust in library administration and the strategic planning process. (Challenge: top-down decision making with little input from exempt and nonexempt employees).

\section{Focus Groups}

The UNCG ClimateQUAL team decided to conduct a series of focus groups in order to gain a deeper understanding of the three most significant concerns so that the libraries could address them effectively. The team engaged the university's Office of Conflict and Peace Studies to assist in this endeavor. In preliminary information sessions, the team informed library staff that focus groups would occur and would be facilitated by a third party. One session was set aside specifically for managers and supervisors so that they did not attend sessions with other staff. These separate sessions were offered in order to provide a safe environment in which non-supervisory staff would feel comfortable speaking up and expressing their opinions.

\section{Sample Focus Group Questions}

The team used the feedback in the information sessions to develop start-up questions for the focus group facilitators to use. Following is a list of sample questions:

Climate for Justice-Distributive Justice-rewards, recognition, and appreciation for effort and work

- Do you feel valued for your efforts? Why or why not?

- What do you like best about working in the University Libraries? 
- To what extent do rewards (recognition and appreciation) received adequately reflect level of effort and work?

- Understanding the limitations on providing direct salary treatment, what other rewards or recognition should be in place to acknowledge accomplishments or reward above-average effort?

Climate for Teamwork-Benefits of Teams and Structural Facilitation of Teamwork-organization's structure and policies facilitate and encourage teamwork

- Considering the climate for teamwork among exempt and non-exempt employees, do you feel there is disparity in the treatment of non-exempt employees compared with exempt employees?

- What are the biggest problems with feeling like there is a lack of teamwork among exempt and nonexempt staff?

- If you could build a new non-exempt and exempt team concept, what would you put in to make a better one?

Climate for Justice-Procedural Justice-fairness of procedures used to determine rewards, performance evaluations, etc.

- Do you feel that information that could impact your job is communicated appropriately and shared evenly?

- Do you feel that decisions are made with appropriate input from the larger organization?

Climate for Job Satisfaction

- When you think about job satisfaction, what is the first thing that comes to mind?

\section{Focus Group Process and Outcomes}

Three focus groups were conducted by the Office of Conflict and Peace Studies-each one was themed to capture summary information that pertains to the measure under consideration. As a matter of process, the focus group facilitators highlighted contributions in each meeting in order to document the conversations. These highlights represent the raw data or comments made during the focus groups that then provide issues for further discussion or analysis. Review of this data-presented graphically in the accompanying word clouds that visualize the frequency of the appearance of specific words in the raw data (Figures 1-3) — can be useful in providing context for the team's recommendations and actions. 
Figure 1. Climate for Justice—Data from Focus Groups

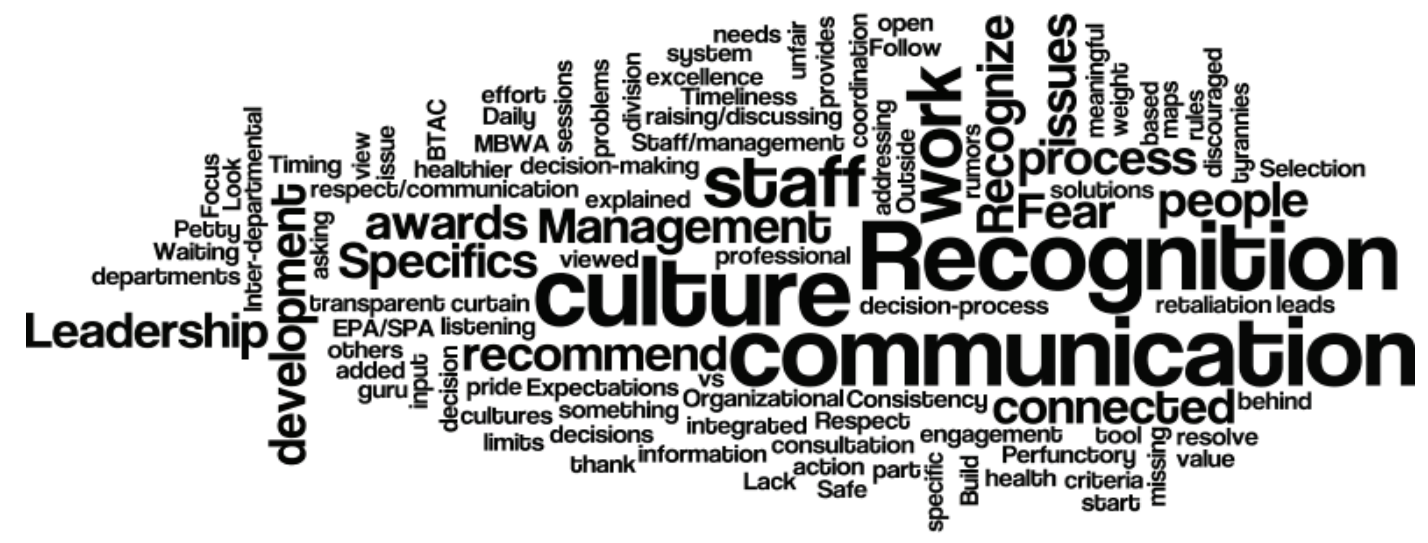

Figure 2. Climate for Team Work—Data from Focus Groups

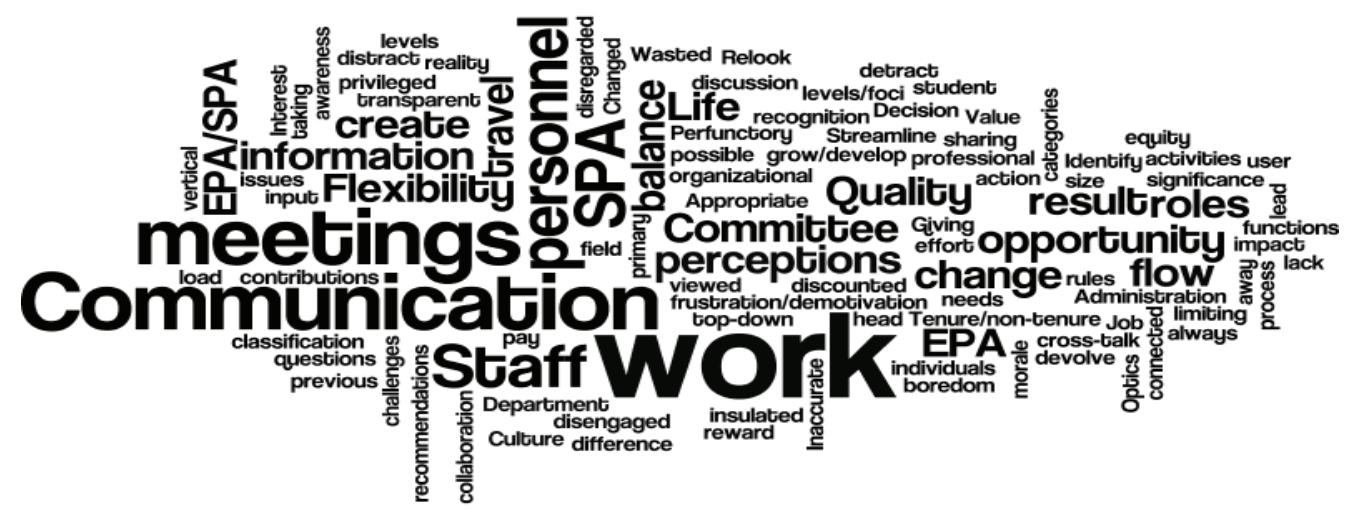

Figure 3. Climate for Job Satisfaction—Data from Focus Groups

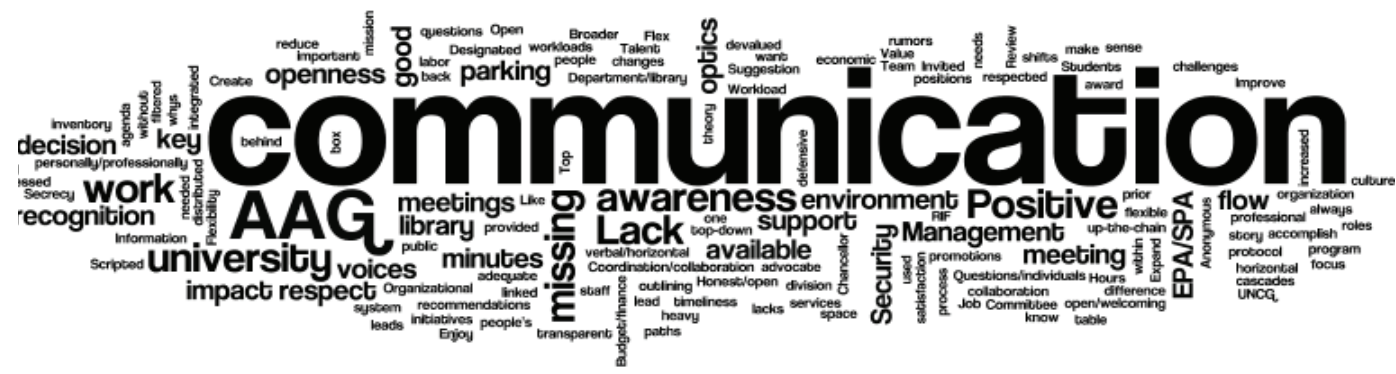


The focus group facilitators synthesized the raw data into basic recommendations with help from the ClimateQUAL team to understand terminology and context. The team then shared the recommendations with managers and supervisors starting with the Administrative Advisory Group.

The AAG (Administrative Advisory Group) is the group made up of assistant/associate deans, department heads, and functional coordinators. The AAG meets once a month, chaired by the dean of the University Libraries. This group was seen as needing to improve communication so that library staff could feel more in touch with decision making and actions impacting the whole of the organization. The feedback recognized the "fear culture" generated in part by larger issues within the campus and economy but challenged the leadership to inform and communicate better. Some summarized desires raised in the focus groups include:

- More transparency in decisions related to staffing and workflows, especially between departments

- More visibility of AAG with staff by interacting at a level to understand job functions better and to gain perspective on workplace needs

- Better recognition of individual efforts, especially when no ability to reward monetarily

- Support for staff development opportunities that benefit both the work place and personal enrichment

- Two-way communication channels that provide the ability to obtain answers or be informed in a timely way and without retribution

- Look at how exempt and non-exempt employees are treated differently and not given the same opportunities

- Address concerns about departments working in silos and creating a culture of being inflexible or unresponsive to the needs of other departments

\section{Strategic Actions for Improvement}

The AAG and the UNCG ClimateQUAL team began developing improvement strategies to address the concerns raised in the focus groups.

\section{Instituting a Staff Recognition Week}

One of the major actions taken by the administration was the development of a Staff Recognition Week in which a series of events would take place during a week identified as low impact in order to allow everyone to participate. A revamped Staff Development Committee was charged with soliciting organizational feedback as to staff members' desires and development needs and with programming the event. The committee solicited staff input through an assessment survey given to the entire staff.

Staff Recognition Week has now taken place twice with smaller single-event activities occurring in the intervening periods. Events and activities are classified or respond to specific needs as derived from the ClimateQUAL data-driven focus groups. Examples of these event types are: personal enrichment, jobrelated skills, health and fitness, teamwork, career enhancement, and communication techniques and 
styles. Suggestions for events are solicited from the staff. The events have a foundation within a diverse set of experiences of existing staff as well as expertise brought in from outside the libraries.

\section{Periodic Town Hall Meetings}

Another strategic action developed from the ClimateQUAL and focus group results directly impacted communication and how to approach sharing information with the entire staff. Traditional communication with the entire staff took place twice a year in an All Personnel Meeting presentation format. Administrators, department heads, and anyone else needing to report information were invited to present at this meeting. From the focus group feedback, this was determined to be seen as one-way communication only and not effective in providing a venue to have a discussion and explain details or reasoning behind programs, actions, or decisions. The University Libraries has now adopted a town-hall style meeting format so that discussion can occur and everyone is invited to speak up to ask questions, seek clarification, or present an opposing viewpoint. Topics and agendas are sent out in advance so that staff have a chance to prepare and meetings are held more frequently so that each single meeting is not overly stuffed with information that becomes rushed or pushed.

\section{More Visible Appreciation and Recognition}

The University Libraries has also put more appreciation gestures into play so that staff members see examples of appreciation more frequently. This includes lower-cost events, such as a cupcake truck that comes to the building and allows everyone to select a cupcake of their choice; more communication with all staff regarding individual accomplishments; and a higher level of recognition for special assignments, committees, task force completions, or team accomplishments to validate that the work performed was appreciated.

\section{Enhanced Information Sharing across All Staff Levels}

Another strategy has been to provide more opportunities for information sharing across non-exempt and exempt staff activities. This includes activities such as sharing presentations, collaborating on projects and information sessions that further explain the role of both professional activities and paraprofessional activities.

Regarding communication, in particular communication from the Administrative Advisory Group, several elements from the focus group feedback were identified for coaching performance. These are ongoing discussions in which members of the AAG are encouraged to share best practices regarding their technique and style. Examples are:

- More specific information from town-hall meeting to be presented into department meetings

- Managers/supervisors need to be more visible throughout the day to all employees

- Staff members should be engaged by managers/supervisors as to their daily work activities to demonstrate that they are valued

- Department heads should work with employees on scheduling flexibility as needed or requested 
Communication also appeared to be random and inconsistent, based on the focus group feedback. A strategy to address that came in the form of a portal for staff communication named "Behind the Stacks." This is a web-based SharePoint portal that links various specialty blogs and provides highlights or announcements for daily events. The portal also includes links to forms and information as well as committee actions and minutes. The specialty blogs provide venues for both personal information, such as birth announcements, selling personal items, etc., and organization-related information, such as human resource information, campus events, and organizational news.

\section{Re-Opening the Open House}

A final strategy that the libraries revisited from the past was an open house concept for library departments to share with one another their work and activities. Departmental open houses are scheduled on a monthly basis. During its open house the department provides information within the work space as to what happens where, and then staff members are present to explain work flows, concepts, etc., and how they are contributing to the department's goals and objectives.

\section{Conclusion}

As of this writing, the libraries completed the ClimateQUAL survey three years ago but most of these strategies put into place from the focus group feedback are less than two years old. It is the organization's intention to reassess in 2015 how these strategies have impacted the organizational climate. Early feedback has been positive, indicating that issues raised have at least been acknowledged if not addressed. In addition, the University Libraries has developed spin-off committees focused on creating recognition and rewards ideas and events, as well as a group looking at ways to improve Behind the Stacks communication.

The University Libraries has continued to experience budget cuts as well as witness other campus actions that have impacted colleagues and friends. The actions that the organization has taken based on the ClimateQUAL survey and resulting focus group feedback have kept staff more informed and better satisfied about decisions being made. The UNCG ClimateQUAL team is optimistic that this experience has made a positive change to the organization.

\section{Endnotes}

1 ClimateQUAL®: Organizational Climate and Diversity Assessment is an assessment of (a) library staff perceptions of the organization's commitment to the principles of diversity, (b) staff perceptions of organizational policies and procedures, and (c) staff attitudes. ARL, in partnership with the University of Maryland Industrial/Organizational Psychology Program, offers the ClimateQUAL protocol to the library community. For more information about ClimateQUAL, see http:// climatequal.org/. 
(C) 2015 Michael Crumpton

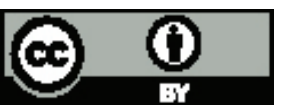

This article is licensed under a Creative Commons Attribution 4.0 International License. To view a copy of this license, visit http://creativecommons.org/licenses/by/4.0/.

To cite this article: Michael Crumpton. "Strategically Focusing on Focus Groups to Improve Organizational Climate" Research Library Issues: A Report from ARL, CNI, and SPARC, no. 286 (2015): 8-17. http://publications.arl.org/rli286/8. 